\title{
Benefits of statin therapy and compliance in high risk cardiovascular patients
}

\author{
This article was published in the following Dove Press journal: \\ Vascular Health and Risk Management \\ 22 September 2010 \\ Number of times this article has been viewed
}

\author{
Joel A Lardizabal' \\ Prakash C Deedwania ${ }^{2}$ \\ 'Division of Cardiology, Department \\ of Medicine, University of California \\ in San Francisco (Fresno-MEP), \\ Fresno, CA, USA; ${ }^{2}$ University of \\ California in San Francisco, Chief of \\ Cardiology, Veterans Affairs Central \\ California System, Fresno, CA, USA
}

Correspondence: Prakash C Deedwania Cardiology Division, VACCHS Medical Center, 2515 East Clinton Avenue, Fresno, CA 93703, USA

$\mathrm{Tel}+\mathrm{I} 559228-5325$

Fax + I 559 228-696 I

Email pdeedwania@fresno.ucsf.edu

\begin{abstract}
Cardiovascular disease (CVD) remains the top cause of global mortality. There is considerable evidence that supports the mortality and morbidity benefit of statin therapy in coronary heart disease (CHD) and stroke, both in primary and secondary prevention settings. Data also exist pointing to the advantage of statin treatment in other high-risk CVD conditions, such as diabetes, CKD, CHF, and PVD. National and international clinical guidelines in the management of these CVD conditions all advocate for the utilization of statin therapy in appropriate patients. However, overall compliance to statin therapy remains suboptimal. Patient-, physician-, and economic-related factors all play a role. These factors need to be considered in devising approaches to enhance adherence to guideline-based therapies. To fully reap the benefits of statin therapy, interventions which improve long-term treatment compliance in realworld settings should be encouraged.
\end{abstract}

Keywords: cardiovascular disease, statin therapy, coronary heart disease, long-term treatment compliance

Cardiovascular disease (CVD) is the leading cause of death worldwide, accounting for nearly $30 \%$ of the annual global mortality. ${ }^{1}$ In the United States, where the disease is highly prevalent, over one third of the population has one or more types of CVD. Coronary heart disease (CHD) affects nearly 18 million Americans. As the predominant cause of death from CVD, it is estimated that over one million individuals suffer from acute CHD events each year in the United States. Stroke, the second leading cause of death from CVD, has a prevalence of nearly 6.5 million, and over 600,000 new stroke cases are diagnosed annually in the United States. ${ }^{2}$ Other forms of high-risk CVD conditions are common as well. Approximately 5 million Americans have been diagnosed with heart failure (HF), and around 8 million Americans with peripheral vascular disease (PVD). Diabetes mellitus, a major CVD risk factor and CHD-equivalent, afflicts approximately 5.5 million individuals in the United States.

Dyslipidemia is one of the major CVD risk factors, and cholesterol-modifying therapy has well-established benefits in the primary and secondary prevention of CHD and stroke. As such, lipid-lowering therapy, primarily with the HMG-CoAreductase inhibitors (statins), has become the mainstay of therapeutic guidelines for the management of these conditions. ${ }^{3,4}$ There is also a growing body of evidence supporting the benefit of statin therapy in other CVD conditions such as heart failure (HF), PVD, and chronic kidney disease (CKD). Furthermore, statin therapy has already been an integral part of the standard management of diabetes mellitus, a major CVD risk factor and CHD-equivalent. ${ }^{5}$ 
Although the burden of CVD remains high, mortality has been on a declining trend, which is largely attributed to evidence-based therapies - especially risk-reduction strategies, including the use of statins. Despite the known benefits, however, a significant proportion of high risk patients with CVD still do not receive the recommended regimens of lipid-modifying therapy, and many others discontinue treatment after being initiated on statin therapy. Improving the compliance to guideline-based therapies by both patients and physicians could potentially further reduce the public health and economic burden imposed by CVD.

\section{Lipids, CVD risk, and statins}

The relationship between abnormal plasma cholesterol fractions and increased CVD risk was described up to 60 years ago, when the role of the different lipoproteins in atherosclerosis was just being elucidated. ${ }^{6}$ The modern concept of atherogenesis highlights the crucial roles these lipoproteins play in the atherosclerotic process. One of the earliest steps in atheroma formation involves the infiltration of the dysfunctional vascular endothelium by low-density lipoprotein cholesterol (LDL), the most atherogenic of the lipoproteins. The LDL in the vessel wall becomes oxidized and is taken up by macrophages forming the classic foam cells. This process further stimulates lipid deposition and incites the inflammatory cascade that leads to the formation of the atherosclerotic plaque. On the other hand, the highdensity lipoprotein cholesterol (HDL) promotes reverse transport of cholesterol from lipid-laden macrophages in the vascular wall, and has anti-inflammatory effects, thereby inhibiting the progression of atherosclerosis and potentially inducing regression of the atherosclerotic plaque. ${ }^{7}$ In various conditions where levels of LDL are abnormally high or levels of HDL are low, the atherosclerotic process is enhanced, increasing the risk of development of CVD.

Statins exert their LDL-lowering effect primarily through the inhibition of the HMG-CoA-reductase enzyme, which mediates the first committed step in the mevalonate pathway of cholesterol synthesis. To a lesser degree, these agents also decrease triglyceride levels, probably through inhibition of its synthesis in the liver and enhancement of lipoprotein lipase enzyme activity in the adipocytes. ${ }^{8}$ Statins also have modest HDL-raising properties, which are postulated to result from the activation of peroxisome proliferator-activated receptors, leading to Apo-A1 gene induction. ${ }^{9}$ It is also theorized that lipid-independent effects of statins contribute to some degree to their anti-atherothrombotic properties. A few of these purported pleiotrophic effects include modulation of inflammatory response, improvement of endothelial function, and inhibition of coagulation. ${ }^{10}$

The earliest statin commercially developed, lovastatin, was released for clinical use in 1987. Several other agents have been marketed since. Clinical data for some of the older statins (eg, lovastatin, pravastatin, simvastatin) showed reductions of $25 \%-39 \%$ in LDL and $8 \%-12 \%$ in triglycerides, as well as a $6 \%-8 \%$ increase in HDL. More potent agents (eg, atorvastatin, rosuvastatin) were later developed, making it possible to achieve even more stringent target lipid goals (up to $55 \%$ reduction in LDL, up to $20 \%$ lowering in triglycerides, and up to $10 \%$ increase in HDL). ${ }^{11,12}$

\section{Statins in the primary prevention of CHD}

Because atherogenic lipoproteins are involved very early in the atherosclerotic process, it is conceivable that treatment with statins could potentially obviate the first onset of CHD events in individuals who are at risk but have not had a previous coronary event. Indeed, analysis of data from primary prevention studies ${ }^{13}$ showed that statin therapy, on average, reduces the risk of overall mortality by $7 \%$ and $\mathrm{MI}$ by $27 \%$ (see Figure 1 ).

In patients with elevated cholesterol levels but without prior history of MI or stroke, the benefit of treatment with statins in the primary prevention of CHD was assessed by the West of Scotland Coronary Prevention Study (WOSCOPS) $)^{14}$ and the more recent Management of Elevated Cholesterol in the Primary Prevention Group of Adult Japanese (MEGA) ${ }^{15}$ trial. With an aggregate sample size of over 14,500 people, in both studies it was demonstrated that pravastatin was associated with reductions in MI (31\% in WOSCOPS, $48 \%$ in MEGA) and mortality ( $32 \%$ in WOSCOPS, $28 \%$ in MEGA) after 5 years of follow-up.

In individuals who have moderate cholesterol levels and are free of overt CVD, statin therapy using lovastatin was associated with reductions in major CHD events by $64 \%$ in the Asymptomatic Carotid Artery Progression Study (ACAPS) ${ }^{16}$ and $37 \%$ in the Air Force/Texas Coronary Atherosclerosis Prevention Study (AFCAPS/TexCAPS). Similarly, in over 10,300 patients with average cholesterol profile and moderate CVD risk, the lipid-lowering arm of the Anglo-Scandinavian Cardiac Outcomes Trial (ASCOT-LLA) ${ }^{17}$ found that low-dose atorvastatin therapy resulted in a $36 \%$ reduction in fatal CHD and nonfatal MI.

In a primary prevention study of nearly 18,000 healthy participants with normal cholesterol profiles but elevated C-reactive protein levels, the Justification for the Use of 


\section{Relative risk $(95 \% \mathrm{Cl})$}

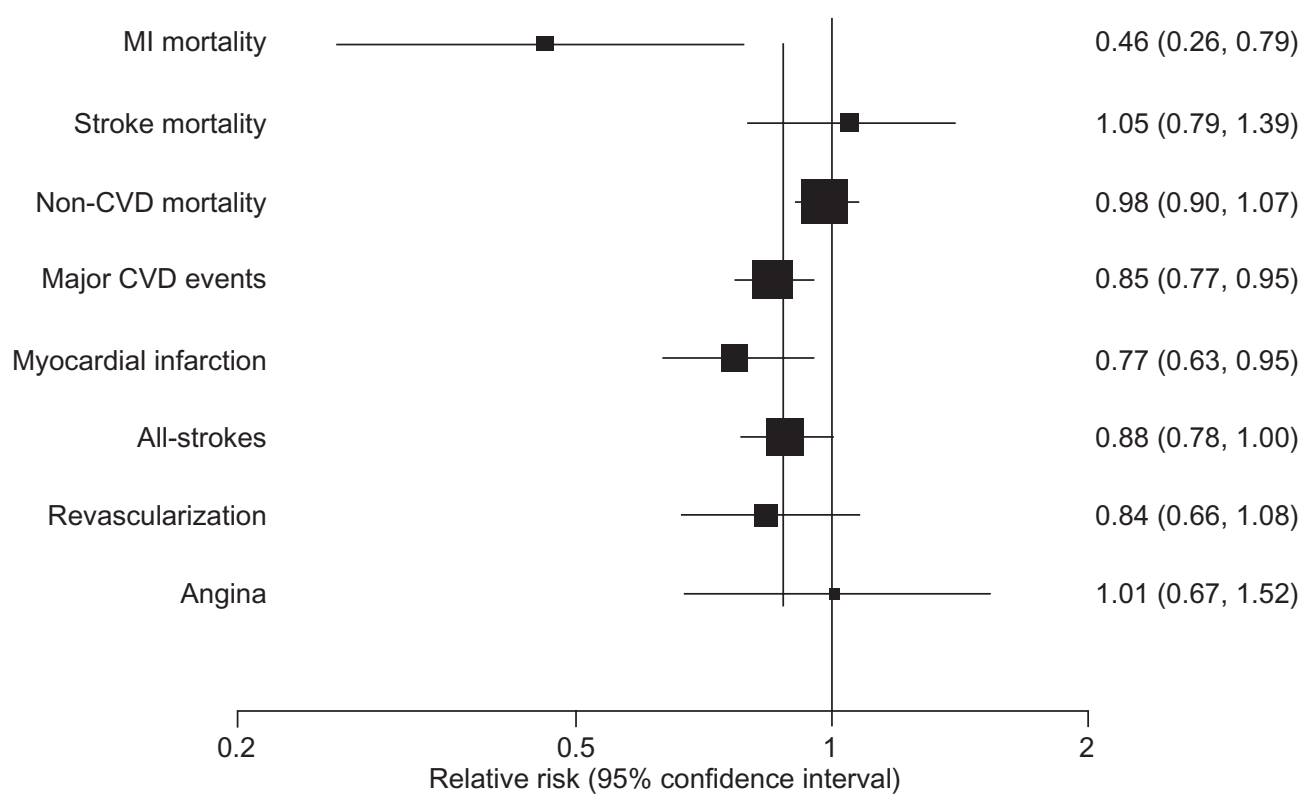

Figure I Plotted estimates of outcomes pooled from primary prevention trials on statin therapy. Pooled relative risk with bars representing $95 \%$ confidence intervals (Cls). Notes: Adapted with permission from Mills EJ, Rachlis B,Wu P, Devereaux PJ,Arora P, Perri D. Primary prevention of cardiovascular mortality and events with statin treatments: a network meta-analysis involving more than 65,000 patients. J Am Coll Cardiol. 2008;52(22): 1769-1781.

Statins in Prevention: an Intervention Trial Evaluating Rosuvastatin (JUPITER $)^{18}$ found that treatment with the agent rosuvastatin led to a $54 \%$ reduction in MI and 20\% mortality reduction in this group of low-risk individuals. How the results of the JUPITER trial impact the current and future standards of clinical preventive therapy remains to be seen.

Lipid-lowering guidelines published before the completion of the JUPITER trial recommend that for primary prevention of CHD in low-risk patients, statin therapy should be started if LDL is above $190 \mathrm{mg} / \mathrm{dL}$, and is only optional if $\mathrm{LDL}>160 \mathrm{mg} / \mathrm{dL}$. Pharmacologic treatment is otherwise not advocated for healthy individuals with $\mathrm{LDL}<160 \mathrm{mg} / \mathrm{dL}$, unless two or more CVD risk factors are present. ${ }^{19}$ To date, there remains no consensus as to the clinical benefit of starting maintenance statin treatment in low-risk, normocholesterolemic individuals.

\section{Statins in the secondary prevention of CHD}

While the debate continues as to whether or not healthy individuals should be treated with statins as a primary preventative measure, the role of statin therapy in the secondary prevention of further CHD events is unquestioned, and has, in fact, revolutionized the medical management of patients with preexisting CVD. The Scandinavian Simvastatin Survival Study $(4 S)^{20}$ was the first large clinical trial to demonstrate such benefit. In this study of 4,444 patients with established CHD, long-term treatment with simvastatin was shown to significantly reduce rates of mortality by $30 \%$ and coronary events by $34 \%$. This was followed by the Cholesterol and Recurrent Events (CARE) trial, in which a 24\% decrease in CHD events with pravastatin was found in over 4,000 patients with prior MI. ${ }^{21}$

The mortality benefit of statin therapy was unclear in the CARE trial, but this was definitively established by the Long-Term Intervention with Pravastatin in Ischemic Disease (LIPID) $)^{22}$ study of over 9,000 patients with unstable CHD. In this trial, pravastatin lowered the overall mortality by $14 \%$ and cardiovascular mortality by $24 \%$, along with a $29 \%$ reduction in MI. The survival advantage of statin therapy was consistent, irrespective of baseline cholesterol level, as illustrated by the Heart Protection Study ${ }^{23}$ involving over 20,500 high-risk patients with CVD. In this trial, simvastatin was associated with significant reductions in all-cause mortality by $13 \%$ and in cardiovascular mortality by $18 \%$, across a wide range of initial LDL levels.

High-dose statin therapy is associated with significantly greater reduction in the rate of progression of atherosclerosis compared to a moderate-intensity regimen in patients with CHD and elevated LDL. ${ }^{24}$ The benefits conferred by intensive statin therapy extends even to those with normal LDL levels, as seen in the Treat to New Targets (TNT) trial, where in over 10,000 patients with CHD and LDL $<130 \mathrm{mg} / \mathrm{dL}$, high-dose 
atorvastatin therapy was superior to low-dose treatment in preventing recurrent CHD events. ${ }^{25}$

In patients with acute coronary syndrome (ACS), the Myocardial Ischemia Reduction with Aggressive Cholesterol Lowering (MIRACL) ${ }^{26}$ study showed that statin therapy using high-dose atorvastatin significantly lowered early recurrent ischemic events by $24 \%$. Also, in the Pravastatin or Atorvastatin Evaluation and Infection Therapy-Thrombolysis In Myocardial Infarction 22 (PROVE IT-TIMI 22) ${ }^{27}$ trial it was found that intensive therapy using high-dose atorvastatin was superior to moderate-intensity treatment using pravastatin in preventing subsequent CHD events in this high-risk group of patients with ACS.

A meta-analysis of 25 trials involving nearly 70,000 patients with CHD found that statin therapy, on average, reduces CVD events by $25 \%$ and overall mortality by $16 \%$, irrespective of pretreatment lipid levels, including those with baseline LDL below $100 \mathrm{mg} / \mathrm{dL}$ (see Figure 2). ${ }^{28}$

The prevailing secondary prevention guidelines for patients with established CHD recommend prompt initiation of statin therapy to achieve a goal LDL $<100 \mathrm{mg} / \mathrm{dL}$, using an intensity sufficient enough to achieve a $30 \%-40 \%$ LDL reduction in high-risk individuals. A target LDL goal $<70 \mathrm{mg} / \mathrm{dL}$ using high-dose statin treatment is also considered desirable. ${ }^{29}$ Additionally, in patients with ACS, including those who underwent revascularization, it is strongly advocated that statin therapy be started regardless of baseline LDL levels. ${ }^{30}$

\section{Statins and cerebrovascular disease}

In addition to the significant reduction in CHD risk, there is also evidence pointing to the advantages of statin therapy

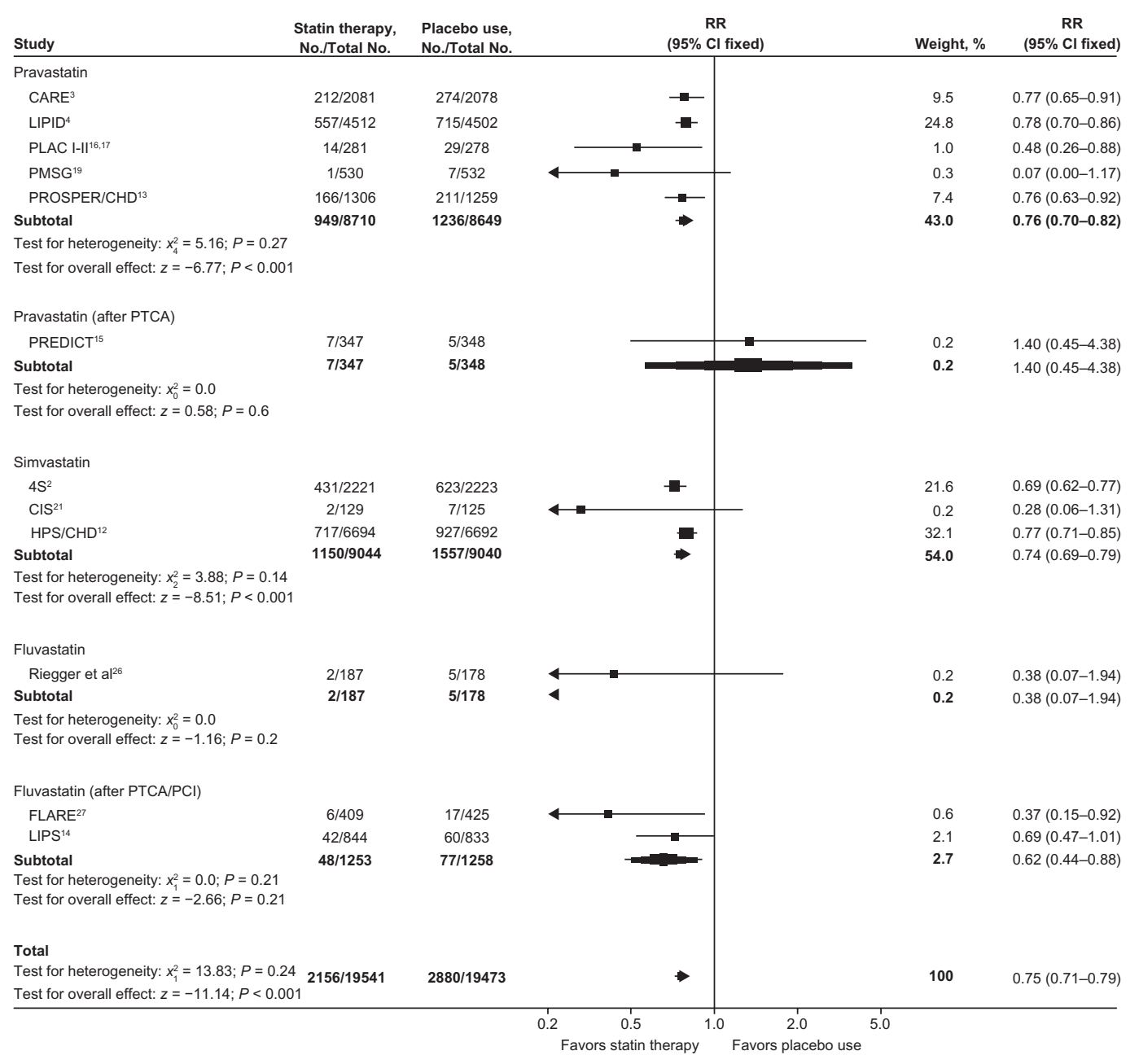

Figure 2 Comparison of relative risks for coronary heart disease mortality and nonfatal myocardial infarction between statin therapy and placebo from the different secondary prevention trials.

Notes: Adapted with permission from Wilt TJ, Bloomfield HE, MacDonald R, et al. Effectiveness of statin therapy in adults with coronary heart disease. Arch Intern Med. 2004; I64(I3): 1427-1436. 
in the primary prevention of stroke. Statin treatment was associated with a $27 \%$ reduction in stroke in high-risk patients enrolled in the ASCOT-LLA primary prevention study. Among low risk patients, on the other hand, statin therapy was associated with a $51 \%$ reduction in ischemic stroke in the JUPITER primary prevention trial. ${ }^{31}$

There are ample data supporting the benefit of statin therapy in the secondary prevention of cerebrovascular events as well. In over 4,700 patients with recent stroke or transient ischemic attack (TIA), in the prospective, randomized Stroke Prevention by Aggressive Reduction in Cholesterol Levels (SPARCL) trial ${ }^{32}$ it was found that treatment with high-dose atorvastatin was associated with significant reductions in the incidence of recurrent stroke by $16 \%$ and CVD events by $20 \%$. In a large registry of patients with ischemic stroke, pretreatment with statins was associated with a $40 \%$ reduction in the odds of poor outcome after stroke in Whites. The same effect, however, was not demonstrated in Blacks. ${ }^{33}$ In elderly individuals with CVD, statin therapy reduced the incidence of TIA by $25 \%$ in the PROSPER trial, although the overall stroke risk was unaffected.

Pooled data from the LIPID, CARE, and WOSCOPS trials, involving nearly 20,000 patients with CHD, showed that pravastatin therapy reduced the total stroke risk by $22 \%$ across a wide range of lipid values. ${ }^{34}$ More recently, the TNT trial demonstrated a $25 \%$ reduction in fatal and nonfatal strokes in CHD patients treated with high-dose compared to low-dose atorvastatin. Also, in patients with ACS, a substudy of the MIRACL trial found that short-term treatment with atorvastatin was associated with a significant $50 \%$ reduction in fatal and nonfatal strokes. ${ }^{35}$

Recommendations on specific target lipid goals and initiation of statin therapy in the primary prevention of cerebrovascular events are the same as that of CHD. ${ }^{36}$ Statins are strongly recommended in patients with stroke or TIA and co-morbid CHD to achieve a target LDL goal $<100 \mathrm{mg} / \mathrm{dL}$, and $\mathrm{LDL}<70 \mathrm{mg} / \mathrm{dL}$ for very high-risk individuals with multiple risk factors. In stroke or TIA patients without concomitant CHD or hyperlipidemia, initiation of statin therapy is considered reasonable for prevention of subsequent CVD events. ${ }^{37}$

\section{Statins and heart failure}

Retrospective analyses of landmark clinical trials on lipidlowering therapy have pointed to the potential beneficial effect of statins in the setting of HF. The earliest clinical data suggesting such effect came from the post-hoc analysis of the $4 \mathrm{~S}$ trial, in which in patients with CHD but without symptomatic HF, simvastatin therapy was associated with a lower incidence of subsequent development of symptomatic HF compared to placebo. In patients with preexisting HF, statin therapy was also linked to a $19 \%$ reduction in mortality. ${ }^{38}$ Similarly, a substudy of the Treating to New Targets (TNT) trial which enrolled 10,000 patients with stable CHD demonstrated that high-dose statin therapy (atorvastatin $80 \mathrm{mg}$ daily) resulted in a $26 \%$ risk reduction in hospitalization for HF compared to low-dose atorvastatin (10 mg daily). This effect was even more prominent (41\% risk reduction) in people who had history of $\mathrm{HF}^{39}$

In patients with known CHD and ischemic HF, analysis of data from the Multicenter Automatic Defibrillator Implantation Trial (MADIT-II) showed that those who used statin $\geq 90 \%$ of the time had a 35\% lower incidence of ventricular arrhythmias or cardiac death compared to participants who took statins less often. ${ }^{40}$ In patients with nonischemic cardiomyopathy, on the other hand, a substudy of the Defibrillators in Non-Ischemic Cardiomyopathy Treatment Evaluation (DEFINITE) trial found a $22 \%$ decrease in appropriate defibrillator shocks and an $84 \%$ reduction in arrhythmic sudden death in participants treated with a statin. ${ }^{41}$

However, large, prospective, randomized trials failed to corroborate these findings. For instance, the Controlled Rosuvastatin Multinational Trial in Heart Failure (CORONA) involving over 5,000 elderly patients with ischemic HF, found no significant beneficial effect of statin treatment with rosuvastatin on risk reduction of CVD events. ${ }^{42}$ Likewise, rosuvastatin treatment had a similar influence as placebo in terms of CVD outcomes in over 4,500 patients with ischemic and non-ischemic HF enrolled in the GISSI-HF trial. ${ }^{43}$

Given the lack of definitive evidence, existing heart failure guidelines do not specifically address the role of statins in heart failure therapy. However, these guidelines do recommend that patients with other concomitant CVD (eg, hyperlipidemia, diabetes or CHD) be treated according to current standards of care. ${ }^{44}$ In this context, statin therapy should be utilized in patients with HF if there are any comorbid conditions requiring its use.

\section{Statins and peripheral vascular disease}

Post-hoc analysis of the Heart Protection Study provided one of the earliest reliable data sets for the beneficial effects of statin therapy in PVD. In over 6,700 patients with known PVD enrolled in the trial, statin therapy using simvastatin was found to be associated with a $22 \%$ reduction in CVD events and a $20 \%$ decrease in noncoronary revascularization, effects 
which appeared to be independent of baseline cholesterol levels. ${ }^{45}$ Small, non-randomized studies also showed that statin use in patients with PVD was linked to significant improvements in walk performance and overall leg function. ${ }^{46,47}$ Pleitrophic effects of statins have been postulated to be responsible for these effects, as the findings appeared to be independent of cholesterol-lowering.

Randomized trials in which a small number of patients with PVD and intermittent claudication were enrolled also demonstrated improvements in overall walking performance, anklebrachial pressure indexes, and symptoms of claudication with statin therapy. Short-term (6 months) treatment with statins, on average, increased pain-free walking distance by 90 meters and symptom-free exercise time by nearly 1 minute. ${ }^{48-50}$

Still lacking, however, are large, multicenter, randomized trials that are adequately powered to confirm the therapeutic advantage of statins on both CVD outcomes as well as symptom/quality-of-life measures. Since this condition is considered a CHD-equivalent, existing guidelines recommend the use of statin therapy to prevent CVD events in all patients with PVD to achieve a target LDL $<100 \mathrm{mg} / \mathrm{dL}$, or lower $(<70 \mathrm{mg} / \mathrm{dL})$ in those with lower extremity PVD at very high risk for ischemic events. ${ }^{51}$ The role of lipid-lowering therapies for treatment of claudication symptoms, however, has yet to be established.

\section{Use of statins in diabetes mellitus}

Early studies on lipid-lowering therapy raised the possibility of a beneficial effect of statins on CVD events in patients with diabetes. Meta-analysis of the LIPID, CARE, and 4S trials found that in diabetic patients, statin therapy was associated with a $28 \%$ reduction in coronary events and a $32 \%$ reduction in stroke, across a wide range of baseline cholesterol levels. The protection from CVD events seen with statins was greater for patients with diabetes than the non-diabetics. ${ }^{52}$

The Heart Protection Study provided the first direct evidence that statin therapy produces reductions in CVD events among people with diabetes. ${ }^{53}$ It was found that among nearly 6,000 patients with known diabetes, treatment with simvastatin was associated with a $22 \%$ reduction in coronary events and strokes, irrespective of comorbid CVD conditions and baseline LDL levels.

The effectiveness of statin therapy in the primary prevention of CVD in patients with diabetes was subsequently established by the Collaborative Atorvastatin Diabetes Study (CARDS). ${ }^{54}$ In this trial of over 2,800 diabetic patients with average cholesterol levels and without preexisting CVD, treatment with atorvastatin led to reductions in CHD events by $36 \%$, stroke by $48 \%$, and mortality by $27 \%$.
Current clinical practice standards recommend statin therapy to achieve an LDL goal $<100 \mathrm{mg} / \mathrm{dL}$ in most patients with diabetes. In those with overt CVD, statin therapy is encouraged regardless of baseline lipid levels, with $\mathrm{LDL}<70 \mathrm{mg} / \mathrm{dL}$ listed as a reasonable goal in these patients. ${ }^{55}$

\section{Statins and chronic kidney disease}

In over 1,700 CHD patients enrolled in the CARE trial with concomitant mild renal dysfunction, statin therapy using pravastatin was associated with a $28 \%$ reduction in coronary events. ${ }^{56}$ In a similar subset of patients in the $4 \mathrm{~S}$ trial, simvastatin treatment was associated with decreases in CHD events by $33 \%$ and in mortality by $31 \% .{ }^{57}$ Of particular note, statin therapy did not appear to reduce the incidence of stroke in these studies of patients with mild CKD.

Patients with moderate CKD were shown to have nearly $50 \%$ higher risk of CVD events compared to those with normal renal function or mild CKD. In a subgroup analysis of the MEGA study, reduction in the incidences of CHD by $48 \%$, stroke by $73 \%$, and mortality by $51 \%$ were seen with pravastatin therapy in patients with moderate CKD. ${ }^{58}$

A recent meta-analysis of 26 trials involving over 25,000 patients with CKD not requiring dialysis found a significant mortality reduction with statin therapy without an increase in adverse events. ${ }^{59}$ However, this benefit did not appear to extend to those with end-stage CKD. The prospective German Diabetes and Dialysis Study (GDDS) randomized over 1,200 diabetic patients on maintenance dialysis to treatment with either atorvastatin or placebo. After 4 years of follow-up, no beneficial effect on CVD events or mortality was seen with atorvastatin therapy. Although statin therapy led to a modest $18 \%$ reduction in combined cardiac events, this was, however, negated by a 2-fold increase in the incidence of fatal stroke. ${ }^{60}$ A similar conclusion was made by the AURORA (A Study to Evaluate the Use of Rosuvastatin in Subjects on Regular Hemodialysis: An Assessment of Survival and Cardiovascular Events) trial, where rosuvastatin treatment showed no significant influence in terms of CHD, stroke, or mortality risk reduction in patients undergoing dialysis, despite a $43 \%$ lowering in LDL. ${ }^{61}$ It is thought that the initiation of lipid-lowering therapy in patients who already have end-stage renal disease may be too late to translate into consistent improvement of outcomes.

The National Kidney Foundation guidelines classify all stages of CKD as CHD-equivalent, and recommend that all patients with CKD be treated to a target LDL $<100 \mathrm{mg} / \mathrm{dL}$. Statin is the initial preferred agent if baseline LDL is above $130 \mathrm{mg} / \mathrm{dL}$ or in patients with Stage 5 CKD (kidney failure or clinical indication for dialysis or transplantation). ${ }^{62}$ 


\section{Compliance to statins in the real world}

Despite the well-established benefits and abundance of clinical management guidelines strongly advocating statin use in high-risk cardiac conditions, long-term adherence to statin regimens in patients who are appropriate candidates has generally been poor, and continued use of statins drops substantially over time. In the WOSCOPS trial, for example, less than $40 \%$ of patients in the original statin group were on a statin 5 years after the study ended. ${ }^{63}$ In one series, the greatest decline occurred during the first 6 months, and only $25 \%$ of patients maintained an acceptable level of compliance to statins 5 years after initiation of therapy. ${ }^{64}$

In patients with CHD, in a recent survey a $26 \%$ rate of noncompliance to statins was found, which was in turn associated with an $85 \%$ increase in overall mortality. ${ }^{65}$ Among those who had ACS, the continuation rate for statin drops to $44 \%$ after 3 years.$^{66}$ Similarly, the stroke survivors' adherence to recommended statin regimens rapidly declines after hospital discharge, and barely half of these patients remain on treatment after 2 years. ${ }^{67}$ Diabetics are not faring any better, with less than half of patients maintaining a satisfactory degree of long-term statin adherence. ${ }^{68}$

The causes for noncompliance are multifactorial. One of the major reasons is the unfounded fear by patients and physicians alike regarding the toxicity of lipid-lowering agents. A major contributor to this anxiety is the glut of information on the Internet on the adverse effects of statins. Such safety concerns, however, are obviously not supported by recent large randomized trials (see Figure 3). Although myalgia without any CPK rise can occur in up to $5 \%$ of statin users, which might be perceived as a side effect, serious adverse events are rare, and statin-induced rhabdomyolysis occurs in less than 1 per 100,000 patients exposed. ${ }^{69}$ Another explanation for the nonadherence of patients to statin therapy is the lack of education and awareness about the long-term benefits of treatment, especially since they do not feel better right away.

Younger age, female gender, black or hispanic ethnicity, higher comorbidity, and lower median income were some of the patient-related predictors of nonadherence to prescribed statin regimen..$^{70}$ Among physician-related factors, patients were more likely to comply if the statin was prescribed by a cardiologist or a primary care doctor. ${ }^{71}$ All these factors need to be considered in devising approaches to enhance adherence to guideline-based therapies.

\section{Interventions to increase adherence to statin regimen}

It is now well-established that the use of statins is associated with lower mortality, and prolongs the lifespan by an average of 2 years, even if therapy is initiated at a more advanced age. ${ }^{72}$ For patients to reap the full protective benefits of statin therapies, however, it is obvious that overall compliance to such regimen needs to be improved.

In individuals and patient groups who are more likely to discontinue treatment, perhaps a more intensive educational

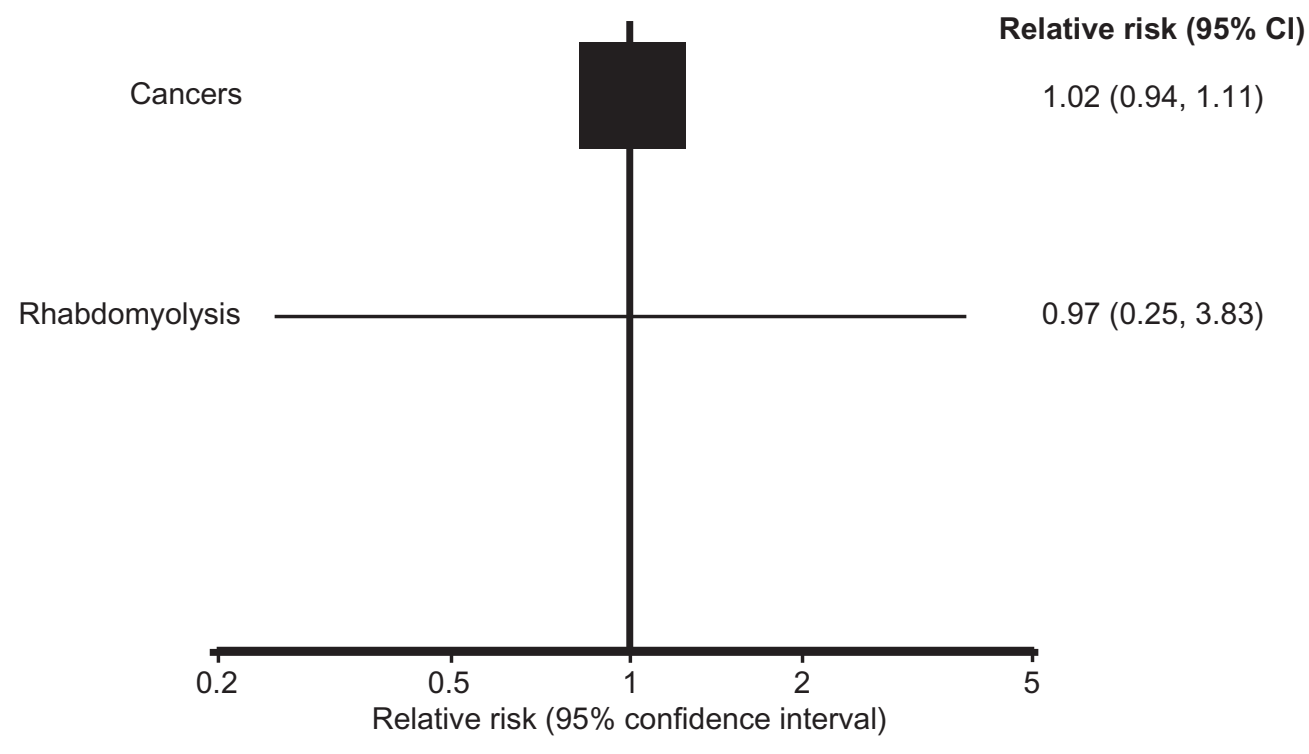

Figure 3 Plotted estimates of adverse events cancer and rhabdomyolysis pooled from primary prevention trials on statin therapy. Pooled relative risk with bars representing $95 \%$ confidence intervals (Cls).

Notes: Adapted with permission from Mills EJ, Rachlis B,Wu P, Devereaux PJ,Arora P, Perri D. Primary prevention of cardiovascular mortality and events with statin treatments: a network meta-analysis involving more than 65,000 patients.J Am Coll Cardiol. 2008;52(22): 1769-178I. 
program (highlighting the safety, and long-term benefits with achieved target LDL) and closer monitoring of compliance could be used to ensure sustained long-term statin use. The utilization of statins by patients has been shown to be dynamic, with over half of new statin users having periods of nonadherence lasting at least 90 days. Regular clinical follow-up visits and serial lipid testing appear to promote reinitiation of therapy in one study, ${ }^{73}$ and can be one of the simpler interventions clinicians can employ to promote longterm statin adherence in most patients.

A multidisciplinary disease-management team approach to patient management has also been shown to improve compliance to statins and other guideline-based therapies. In a single-center interventional program for patients who underwent coronary artery bypass surgery, a quality improvement team consisting of thoracic surgeons, clinical pharmacists, dieticians, physical therapists, and nurse coordinators, implemented a goal-directed approach to postoperative care, which resulted in a significantly higher adherence to recommended therapies on hospital discharge. ${ }^{74}$ This is important since it is known that prescription for statins at the time of hospital discharge enhances long-term statin compliance. ${ }^{75}$ A similarly structured cardiac rehabilitation program may also exert a favorable impact on the sustained adherence to statins and other essential medications in the outpatient setting. ${ }^{76}$

Another possible reason for poor utilization of statins is that some healthcare providers may fail to prescribe them in appropriate patients. Hence, compliance to the recommended therapies by physicians needs to be addressed as well. National and institution-based initiatives to promote adherence to guideline-based therapies, including statin utilization, in high-risk CVD patients have been shown to be effective and have resulted in improved outcomes. Among those successfully implemented include the Get-With-TheGuidelines (GTWG) initiative, the Guidelines Applied in Practice (GAP) project, and the Cardiac Hospitalization Atherosclerosis Management Program (CHAMP).

CHAMP, which was initiated at a large university hospital, implemented a simplified treatment algorithm that focused improving utilization of statins and other guideline-based therapies before hospital discharge in patients with CHD. Comparison of outcomes before and after the program started showed that CHAMP was associated with a significant increase in use of recommended medications, and an increase in the proportion of patients achieve target lipid goals, which subsequently led to significant reductions in recurrent $\mathrm{MI}$ and mortality. ${ }^{77}$

The GAP project was promoted by the American College of Cardiology and was adopted by 33 participating hospitals.
The program aimed to foster systems-based hospital care of ACS patients from admission to discharge, incorporating standard, evidence-based tools into practice and targeting patients, physicians, and nurses. In hospitalized patients with ACS, the improved adherence to statins and other guideline-based therapies associated with the project was demonstrated to result in significant lowering of short-term and long-term mortality. ${ }^{78}$

The GTWG quality improvement initiative, on the other hand, was implemented by the American Heart Association to optimize and standardize the hospital care for patients with CHD, stroke, and HF. In nearly 1,500 voluntarilyparticipating hospitals, this program has improved the compliance to recommended therapies in the inpatient setting, which translated to improvement in CVD outcomes. ${ }^{79}$ In patients with high-risk CVD, adherence to GWTG quality measures has eliminated or at least diminished the age-, gender-, racial-, and ethnicity-related disparities in hospital care ${ }^{80-82}$ The benefits of participation in the GTWG program have also been shown to persist over time, independent of hospital characteristics. ${ }^{83}$

Initiatives like the GTWG are excellent models by which to pattern interventions to enhance statin compliance, especially if such programs are expanded to include the outpatient and general community setting. From a regulatory perspective, the core measures and the accreditation standards set forth by the Joint Commission on Accreditation of Healthcare Organizations (JCAHO) for MI, HF, stroke, and CKD are another powerful venue where utilization of guideline-based therapies can potentially be enhanced. Inclusion of the use of statins in the JCAHO quality measures for these patients with high-risk CVD would certainly improve adherence to such agents.

Higher drug prescription co-payment costs and insurance cost-sharing schemes adversely affect adherence to lipidlowering therapies. In high-risk patients who need statins the most, full out-of-pocket spending for drug prescription nearly doubles the likelihood of stopping treatment. ${ }^{84}$ On a broader economic perspective, elimination of out-of-pocket costs may be an appropriate, cost-effective public health strategy (by reducing the need for hospitalization and expensive procedures) to enhance long-term compliance to statin therapy. While an increase in statin utilization might increase drugrelated expenditure in the short term, this is counterbalanced eventually by the expected benefits in terms of mortality and morbidity reduction. In a recent Medicare cost-effectiveness model analysis, it was projected that full drug coverage for secondary prevention therapies would result in greater functional life expectancy and less resource utilization, a move that appears highly cost-effective in the long term. ${ }^{85}$ 


\section{Conclusion}

An overwhelming amount of data that confirm the morbidity and mortality benefit of statin therapy in high-risk CVD conditions have been reported, both in the primary and secondary prevention settings. National and international clinical guidelines in the management of CHD, stroke, diabetes, CKD, CHF, and PVD all advocate the utilization of statin therapy in appropriate patients. However, overall compliance to statin therapy remains suboptimal. Patient-, physician-, and economic-related factors all play a role. These factors need to be considered in devising approaches to enhance adherence to guideline-based therapies. To fully benefit from the potential of these agents, interventions which improve long-term treatment compliance in real-world settings should be encouraged.

\section{Disclosure}

The authors report no conflicts of interest in this work.

\section{References}

1. The global burden of disease: 2004 update. World Health Organization 2008.

2. American Heart Association Statistics Committee and Stroke Statistics Subcommittee. Executive Summary: Heart Disease and Stroke Statistics - 2010 Update: a report from the American Heart Association. Circulation. 2010;121(7):948-954.

3. Smith SC Jr, Allen J, Blair SN, et al. AHA/ACC guidelines for secondary prevention for patients with coronary and other atherosclerotic vascular disease: 2006 update: endorsed by the National Heart, Lung, and Blood Institute. Circulation. 2006;113(19):2363-2372.

4. Primary prevention of ischemic stroke: a guideline from the American Heart Association/American Stroke Association Stroke Council: cosponsored by the Atherosclerotic Peripheral Vascular Disease Interdisciplinary Working Group; Cardiovascular Nursing Council; Clinical Cardiology Council; Nutrition, Physical Activity, and Metabolism Council; and the Quality of Care and Outcomes Research Interdisciplinary Working Group. Circulation. 2006;113(24):e873-e923.

5. American Diabetes Association. Standards of medical care in diabetes: 2008. Diabetes Care 2008;31:S12-S54.

6. Barr DP, Russ EM, Eder HA. Protein-lipid relationships in human plasma. II. In atherosclerosis and related conditions. Am J Med. 1951; 11(4):480-493.

7. Fuster V, Moreno PR, Fayad ZA, Corti R, Badimon JJ. Atherothrombosis and high-risk plaque: part I: evolving concepts. J Am Coll Cardiol. 2005;46(6):937-954.

8. Saiki A, Murano T, Watanabe F, et al. Pitavastatin enhanced lipoprotein lipase expression in 3T3-L1 preadipocytes. J Atheroscler Thromb. 2005; 12(3):163-168.

9. Yano M, Matsumura T, Senokuchi T, et al. Statins activate peroxisome proliferator-activated receptor gamma through extracellular signalregulated kinase $1 / 2$ and p38 mitogen-activated protein kinasedependent cyclooxygenase-2 expression in macrophages. Circ Res. 2007;100(10):1442-1451.

10. Ray KK, Cannon CP. The potential relevance of the multiple lipid-independent (pleiotropic) effects of statins in the management of acute coronary syndromes. J Am Coll Cardiol. 2005;46(8):1425-1433.

11. Lardizabal JA, Deedwania PC. Low levels of high-density lipoprotein cholesterol and increased cardiovascular disease risk. Asia-Pacific J Cardiol. 2010.
12. Jones PH, Davidson MH, Stein EA, et al. Comparison of the efficacy and safety of rosuvastatin versus atorvastatin, simvastatin, and pravastatin across doses (STELLAR* Trial). Am J Cardiol. 2003;92(2): $152-160$.

13. Mills EJ, Rachlis B, Wu P, Devereaux PJ, Arora P, Perri D. Primary prevention of cardiovascular mortality and events with statin treatments: a network meta-analysis involving more than 65,000 patients. $\mathrm{J} \mathrm{Am} \mathrm{Coll}$ Cardiol. 2008;52(22):1769-1781.

14. Shepherd J, Cobbe SM, Ford I, et al. Prevention of coronary heart disease with pravastatin in men with hypercholesterolemia. N Engl J Med. 1995;333:1301-1307.

15. Nakamura H, Arakawa K, Itakura H, et al. Primary prevention of cardiovascular disease with pravastatin in Japan (MEGA Study): a prospective randomised controlled trial. Lancet. 2006;368(9542):1155-1163.

16. Furberg CD, Adams HP Jr, Applegate WB, et al. Effect of lovastatin on early carotid atherosclerosis and cardiovascular events. Asymptomatic Carotid Artery Progression Study (ACAPS) Research Group. Circulation. 1994;90(4):1679-1687.

17. Sever PS, Dahlöf B, Poulter NR, et al. Prevention of coronary and stroke events with atorvastatin in hypertensive patients who have average or lower-than-average cholesterol concentrations, in the Anglo-Scandinavian Cardiac Outcomes Trial - Lipid Lowering Arm (ASCOT-LLA): a multicentre randomised controlled trial. Lancet. 2003;361(9364):1149-1158.

18. Ridker PM, Danielson E, Fonseca FAG, et al. JUPITER Study Group. Rosuvastatin to prevent vascular events in men and women with elevated C-reactive protein. $N$ Engl J Med. 2008;359(21):2195-2207.

19. The Coordinating Committee of the National Cholesterol Education Program. Implications of recent clinical trials for the National Cholesterol Education Program Adult Treatment Panel III Guidelines. Circulation. 2004;110:227-239.

20. The 4 S Investigators. Randomised trial of cholesterol lowering in 4444 patients with coronary heart disease: the Scandinavian Simvastatin Survival Study (4S). Lancet. 1994;344(8934):1383-1389.

21. Sacks FM, Pfeffer MA, Moye LA, et al. The effect of pravastatin on coronary events after myocardial infarction in patients with average cholesterol levels. Cholesterol and Recurrent Events Trial investigators. N Engl J Med. 1996;335(14):1001-1009.

22. The Long-Term Intervention with Pravastatin in Ischaemic Disease (LIPID) Study Group. Prevention of cardiovascular events and death with pravastatin in patients with coronary heart disease and a broad range of initial cholesterol levels. N Engl J Med. 1998;339(19): 1349-1357.

23. Heart Protection Study Collaborative Group. MRC/BHF Heart Protection Study of cholesterol lowering with simvastatin in 20,536 high-risk individuals: a randomised placebo-controlled trial. Lancet. 2002; 360(9326):7-22.

24. Nissen SE, Tuzcu EM, Schoenhagen P, et al. Reversal of Atherosclerosis with Aggressive Lipid Lowering (REVERSAL) Investigators. Statin therapy, LDL cholesterol, C-reactive protein, and coronary artery disease. N Engl J Med. 2005;352(1):29-38.

25. LaRosa JC, Deedwania PC, Shepherd J, et al; TNT Investigators. Comparison of 80 versus $10 \mathrm{mg}$ of atorvastatin on occurrence of cardiovascular events after the first event (from the Treating to New Targets [TNT] trial). Am J Cardiol. 2010;105(3):283-287.

26. Schwartz GG, Olsson AG, Ezekowitz MD, et al; Myocardial Ischemia Reduction with Aggressive Cholesterol Lowering (MIRACL) Study Investigators. Effects of atorvastatin on early recurrent ischemic events in acute coronary syndromes: the MIRACL study: a randomized controlled trial. JAMA. 2001;285(13):1711-17118.

27. Murphy SA, Cannon CP, Wiviott SD, McCabe CH, Braunwald E. Reduction in recurrent cardiovascular events with intensive lipidlowering statin therapy compared with moderate lipid-lowering statin therapy after acute coronary syndromes from the PROVE IT-TIMI 22 (Pravastatin or Atorvastatin Evaluation and Infection TherapyThrombolysis In Myocardial Infarction 22) trial. J Am Coll Cardiol. 2009;54(25):2358-2362. 
28. Wilt TJ, Bloomfield HE, MacDonald R, et al. Effectiveness of statin therapy in adults with coronary heart disease. Arch Intern Med. 2004; 164(13):1427-1436.

29. Smith SC, Allen J, Blair SN, et al. AHA/ACC guidelines for secondary prevention for patients with coronary and other atherosclerotic vascular disease: 2006 update. Circulation. 2006;113:2363-2372.

30. ACC/AHA 2007 guidelines for the management of patients with unstable angina/non-ST-elevation myocardial infarction: a report of the American College of Cardiology/American Heart Association Task Force on Practice Guidelines (Writing Committee to Revise the 2002 Guidelines for the Management of Patients With Unstable Angina/ Non-ST-Elevation Myocardial Infarction): developed in collaboration with the American College of Emergency Physicians, American College of Physicians, Society for Academic Emergency Medicine, Society for Cardiovascular Angiography and Interventions, and Society of Thoracic Surgeons. J Am Coll Cardiol. 2007;50:e1-e157.

31. Everett BM, Glynn RJ, MacFadyen JG, Ridker PM. Rosuvastatin in the prevention of stroke among men and women with elevated levels of C-reactive protein: Justification for the Use of Statins in Prevention: an Intervention Trial Evaluating Rosuvastatin (JUPITER). Circulation. 2010;121(1):143-150.

32. Stroke Prevention by Aggressive Reduction in Cholesterol Levels (SPARCL) Investigators. High-dose atorvastatin after stroke or transient ischemic attack. Engl J Med. 2006;355(6):549-559.

33. Reeves MJ, Gargano JW, Luo Z, et al. Paul Coverdell National Acute Stroke Registry Michigan Prototype Investigators. Effect of pretreatment with statins on ischemic stroke outcomes. Stroke. 2008; 39(6):1779-1785.

34. Byington RP, Davis BR, Plehn JF, et al. Reduction of stroke events with pravastatin: the Prospective Pravastatin Pooling (PPP) Project. Circulation. 2001;103(3):387-392.

35. Waters DD, Schwartz GG, Olsson AG, et al. Effects of atorvastatin on stroke in patients with unstable angina or non-Q-wave myocardial infarction: a Myocardial Ischemia Reduction with Aggressive Cholesterol Lowering (MIRACL) substudy. Circulation. 2002;106(13): 1690-1695.

36. Primary prevention of ischemic stroke: a guideline from the American Heart Association/American Stroke Association Stroke Council: cosponsored by the Atherosclerotic Peripheral Vascular Disease Interdisciplinary Working Group; Cardiovascular Nursing Council; Clinical Cardiology Council; Nutrition, Physical Activity, and Metabolism Council; and the Quality of Care and Outcomes Research Interdisciplinary Working Group. Circulation. 2006;113(24): e873-e923.

37. Guidelines for prevention of stroke in patients with ischemic stroke or transient ischemic attack: a statement for healthcare professionals from the American Heart Association/American Stroke Association Council on Stroke: co-sponsored by the Council on Cardiovascular Radiology and Intervention: the American Academy of Neurology affirms the value of this guideline. Stroke. 2006;37(2):577-617.

38. Deedwania PC, Javed U. Statins in heart failure. Cardiol Clin. 2008; 26(4):573-587.

39. Khush KK, Waters DD, Bittner V, et al. Effect of high-dose atorvastatin on hospitalizations for heart failure: subgroup analysis of the Treating to New targets (TNT) Study. Circulation. 2007;115: $576-583$.

40. Vyas AK, Guo H, Moss AJ, et al. Reduction in ventricular tachyarrhythmias with statins in the Multicenter Automatic Defibrillator Implantation Trial (MADIT)-II. J Am Coll Cardiol. 2006;47: 769-773.

41. Goldberger JJ, Subacius H, Schaechter A, et al. Effects of statin therapy on arrhythmic events and survival in patients with nonischemic dilated cardiomyopathy. J Am Coll Cardiol. 2006;48:1228-1233.

42. The CORONA Investigators. Rosuvastatin in older patients with systolic heart failure. N Engl J Med. 2007;357:2248-2261.

43. Gissi-HF Investigators. Effect of rosuvastatin in patients with chronic heart failure (the GISSI-HF trial): a randomised, double-blind, placebocontrolled trial. Lancet. 2008;372(9645):1231-1239.
44. Hunt SA, Abraham WT, Chin MH, et al. 2009 focused update incorporated into the ACC/AHA 2005 guidelines for the diagnosis and management of heart failure in adults: a report of the American College of Cardiology Foundation/American Heart Association Task Force on Practice Guidelines. J Am Coll Cardiol. 2009;53: e1-e90.

45. Heart Protection Study Collaborative Group. Randomized trial of the effects of cholesterol-lowering with simvastatin on peripheral vascular and other major vascular outcomes in 20,536 people with peripheral arterial disease and other high-risk conditions. JVasc Surg. 2007;45(4): 645-654.

46. McDermott MM, Guralnik JM, Greenland P, et al. Statin use and leg functioning in patients with and without lower-extremity peripheral arterial disease. Circulation. 2003;107(5):757-761.

47. Giri J, McDermott MM, Greenland P, et al. Statin use and functional decline in patients with and without peripheral arterial disease. $\mathrm{J} \mathrm{Am} \mathrm{Coll}$ Cardiol. 2006;47(5):998-1004.

48. Mondillo S, Ballo P, Barbati R, et al. Effects of simvastatin on walking performance and symptoms of intermittent claudication in hypercholesterolemic patients with peripheral vascular disease. Am J Med. 2003; 114(5):359-364.

49. Aronow WS, Nayak D, Woodworth S, Ahn C. Effect of simvastatin versus placebo on treadmill exercise time until the onset of intermittent claudication in older patients with peripheral arterial disease at six months and at one year after treatment. Am J Cardiol. 2003;92(6): 711-712.

50. Mohler ER, Hiatt WR, Creager MA. Cholesterol reduction with atorvastatin improves walking distance in patients with peripheral arterial disease. Circulation. 2003;108(12):1481-1486.

51. ACC/AHA 2005 Practice Guidelines for the management of patients with peripheral arterial disease (lower extremity, renal, mesenteric, and abdominal aortic): a collaborative report from the American Association for Vascular Surgery/Society for Vascular Surgery, Society for Cardiovascular Angiography and Interventions, Society for Vascular Medicine and Biology, Society of Interventional Radiology, and the ACC/AHA Task Force on Practice Guidelines (Writing Committee to Develop Guidelines for the Management of Patients With Peripheral Arterial Disease): endorsed by the American Association of Cardiovascular and Pulmonary Rehabilitation; National Heart, Lung, and Blood Institute; Society for Vascular Nursing; TransAtlantic Inter-Society Consensus; and Vascular Disease Foundation. Circulation. 2006;113(11):e463-e654.

52. The LIPID Study Group. Secondary prevention of cardiovascular events with long-term pravastatin in patients with diabetes or impaired fasting glucose: results from the LIPID trial. Diabetes Care. 2003;26: 2713-2721.

53. Heart Protection Study Collaborative Group. MRC/BHF Heart Protection Study of cholesterol-lowering with simvastatin in 5963 people with diabetes: a randomised placebo controlled trial. Lancet. 2003;361: 2005-2016.

54. The CARDS Investigators. Primary prevention of cardiovascular disease with atorvastatin in type 2 diabetes in the Collaborative Atorvastatin Diabetes Study (CARDS): multicentre randomised placebo-controlled trial. Lancet. 2004;364:685-696.

55. American Diabetes Association. Standards of medical care in diabetes 2008. Diabetes Care. 2008;31:S12-S54.

56. Cholesterol and Recurrent Events (CARE) Trial Investigators. Pravastatin for secondary prevention of cardiovascular events in persons with mild chronic renal insufficiency. Ann Intern Med. 2003;138(2): 98-104.

57. Chonchol M, Cook T, Kjekshus J, et al. Simvastatin for secondary prevention of all-cause mortality and major coronary events in patients with mild chronic renal insufficiency. Am J Kidney Dis. 2007;49(3): 373-382.

58. MEGA Study Group. Pravastatin and cardiovascular risk in moderate chronic kidney disease. Atherosclerosis. 2009;206(2):512-517.

59. Navaneethan SD, Pansini F, Perkovic V, et al. HMG CoA reductase inhibitors (statins) for people with chronic kidney disease not requiring dialysis. Cochrane Database Syst Rev. 2009;(2):CD007784. 
60. German Diabetes and Dialysis Study Investigators. Atorvastatin in patients with type 2 diabetes mellitus undergoing hemodialysis. $N E n g l$ J Med. 2005;353(3):238-248.

61. AURORA Study Group. Rosuvastatin and cardiovascular events in patients undergoing hemodialysis. N Engl J Med. 2009;360(14): 1395-1407.

62. National Kidney Foundation. K/DOQI Clinical Practice Guidelines for Managing Dyslipidemias in Chronic Kidney Disease. Am J Kidney Dis. 2003;41:S1-S2.

63. Ford I, Murray H, Packard CJ, et al. Long-term follow-up of the West of Scotland Coronary Prevention Study. N Engl J Med. 2007;357(15): 1477-1486.

64. Benner JS, Glynn RJ, Mogun H, et al. Long-term persistence in use of statin therapy in elderly patients. JAMA. 2002;288(4):455-461.

65. Ho PM, Magid DJ, Shetterly SM, et al. Medication nonadherence is associated with a broad range of adverse outcomes in patients with coronary artery disease. Am Heart J. 2008;155(4):772-729.

66. Shah ND, Dunlay SM, Ting HH, et al. Long-term medication adherence after myocardial infarction: experience of a community. Am J Med. 2009;122(10):e7-e13.

67. Glader EL, Sjölander M, Eriksson M, Lundberg M. Persistent use of secondary preventive drugs declines rapidly during the first 2 years after stroke. Stroke. 2010;41(2):397-401.

68. Donnelly LA, Doney AS, Morris AD, Palmer CN, Donnan PT. Longterm adherence to statin treatment in diabetes. Diabet Med. 2008;25(7): $850-855$.

69. Thompson PD, Clarkson PM, Rosenson RS; National Lipid Association Statin Safety Task Force Muscle Safety Expert Panel. An assessment of statin safety by muscle experts. Am J Cardiol. 2006;97: 69C-76C.

70. Yang Y, Thumula V, Pace PF, et al. Predictors of medication nonadherence among patients with diabetes in Medicare Part D programs: a retrospective cohort study. Clin Ther. 2009;31(10):2178-2188.

71. Chan DC, Shrank WH, Cutler D, et al. Patient, physician, and payment predictors of statin adherence. Med Care. 2010;48(3):196-202.

72. Mehta JL, Bursac Z, Hauer-Jensen M, Fort C, Fink LM. Comparison of mortality rates in statin users versus nonstatin users in a United States veteran population. Am J Cardiol. 2006;98(7):923-928.

73. Brookhart MA, Patrick AR, Schneeweiss S, et al. Physician followup and provider continuity are associated with long-term medication adherence: a study of the dynamics of statin use. Arch Intern Med. 2007;167(8):847-852.

74. Yam FK, Akers WS, Ferraris VA, et al. Interventions to improve guideline compliance following coronary artery bypass grafting. Surgery. 2006;140(4):541-547.
75. Muhlestein JB, Horne BD, Bair TL, et al. Usefulness of in-hospital prescription of statin agents after angiographic diagnosis of coronary artery disease in improving continued compliance and reduced mortality. Am J Cardiol. 2001;87(3):257-261.

76. Jelinek M, Vale MJ, Liew D, et al. The $\mathrm{COACH}$ program produces sustained improvements in cardiovascular risk factors and adherence to recommended medications-two years follow-up. Heart Lung Circ. 2009;18(6):388-392.

77. Fonarow GC, Gawlinski A, Moughrabi S, Tillisch JH. Improved treatment of coronary heart disease by implementation of a Cardiac Hospitalization Atherosclerosis Management Program (CHAMP). Am J Cardiol. 2001;87(7):819-822.

78. Eagle KA, Montoye CK, Riba AL, et al. Guideline-based standardized care is associated with substantially lower mortality in medicare patients with acute myocardial infarction: the American College of Cardiology's Guidelines Applied in Practice (GAP) Projects in Michigan. J Am Coll Cardiol. 2005;46(7):1242-1248.

79. Heidenreich PA, Lewis WR, LaBresh KA, Schwamm LH, Fonarow GC Hospital performance recognition with the Get With The Guidelines Program and mortality for acute myocardial infarction and heart failure. Am Heart J. 2009;158(4):546-553.

80. Lewis WR, Ellrodt AG, Peterson EH, et al. Trends in the use of evidencebased treatments for coronary artery disease among women and the elderly: findings from the get with the guidelines quality-improvement program. Circ Cardiovasc Qual Outcomes. 2009;2(6):633-641.

81. Cohen MG, Fonarow GC, Peterson ED, et al. Racial and Ethnic Differences in the Treatment of Acute Myocardial Infarction. Findings From the Get With The Guidelines-Coronary Artery Disease Program. Circulation. 2010 May 17. [Epub ahead of print].

82. Schwamm LH, Reeves MJ, Pan W, et al. Race/ethnicity, quality of care, and outcomes in ischemic stroke. Circulation. 2010;121(13): 1492-501

83. Xian Y, Pan W, Peterson ED, et al. Are quality improvements associated with the Get With the Guidelines-Coronary Artery Disease (GWTGCAD) program sustained over time? A longitudinal comparison of GWTG-CAD hospitals versus non-GWTG-CAD hospitals. Am Heart J. 2010;159(2):207-214.

84. Schneeweiss S, Patrick AR, Maclure M, Dormuth CR, Glynn RJ. Adherence to statin therapy under drug cost sharing in patients with and without acute myocardial infarction: a population-based natural experiment. Circulation. 2007;115(16):2128-2135.

85. Choudhry NK, Patrick AR, Antman EM, Avorn J, Shrank WH. Costeffectiveness of providing full drug coverage to increase medication adherence in post-myocardial infarction Medicare beneficiaries Circulation. 2008;117(10):1261-1268.
Vascular Health and Risk Management

\section{Publish your work in this journal}

Vascular Health and Risk Management is an international, peerreviewed journal of therapeutics and risk management, focusing on concise rapid reporting of clinical studies on the processes involved in the maintenance of vascular health; the monitoring, prevention and treatment of vascular disease and its sequelae; and the involvement of

\section{Dovepress}

metabolic disorders, particularly diabetes. This journal is indexed on PubMed Central and MedLine. The manuscript management system is completely online and includes a very quick and fair peer-review system, which is all easy to use. Visit http://www.dovepress.com/ testimonials.php to read real quotes from published authors. 